\title{
TRADUÇÃO \\ Crise do poder: Teses para a teoria da contradição dialética ${ }^{1}$
}

\author{
Michael Theunissen
}

I.

1. No seu desdobramento sistemático, a filosofia hegeliana pretende recobrir o único pressuposto do qual ela parte: o de que a razão tem em si [an sich] a força para sua realização [Realisierung] ou, melhor ainda, o de que ela é tal força. Realizar-se significa: abarcar a [übergreifen auf] realidade. A razão é o poder do abarcar. Por isso Hegel a pensa como conceito. Ao "conceito empoderado" (Wissenschaft der Logik, ed. Lasson, II 410 - doravante: L), ao conceito enquanto tal [schlechthin], defrontase na realidade [Realität] "seu outro". No processo da lógica, porém, o conceito já se realiza idealmente [ideell] quando se dispersa [auseinanderlegt] nos "conceitos determinados"; e também esses, determinações de pensamento singulares, possuem cada um o "seu Outro". Assim que seu desenvolvimento - já tendencialmente, com o aprofundamento da Lógica do Ser na Lógica da Essência, e, em seguida, explicitamente no começo da declarada Lógica do Conceito - atinge o patamar que permite a formação [Bildung] do próprio conceito em direção à determinidade da ideia, sua relação [Beziehung] ${ }^{2}$ recíproca assume também a forma do abarcar: a impotência do passar [Übergehen] de algo em algo diferente, característica da lógica do ser, metamorfoseia-se no poder através do qual o um pode enfim reter o outro propriamente como seu outro. Todas as relações nas quais o um se apropria do outro como seu outro, mesmo quando o abarcar genuinamente conceitual ainda não

1 Tradução de Theunissen, M. (1975). „Krise der Macht“. In: Hegel-Jahrbuch. Köln: Pahl-Rugenstein Verlag, p. 318-329, por Bruno Höfig (Universidade de Londres) e Leonardo André Paes Müller (Universidade de São Paulo). Agradecemos a presteza e, acima de tudo, a gentileza de Viola e Oliver Theunissen, herdeiros da obra de Michael Theunissen, que autorizaram a publicação desta tradução. Agradecemos ao professor Georg Löhmann, que mediou o contato com os herdeiros de Theunissen, e ao professor Marcos Lutz Müller, que forneceu o contato do professor Löhmann. Agradecemos aos professores Andreas Arndt e Tilo Wesche o auxílio na busca pela autorização. Por fim, agradecemos as correções e valiosas sugestões ao professor Jorge Grespan e a um parecerista anônimo da revista. Os erros que ainda persistem são de nossa inteira responsabilidade. (Nota dos tradutores - doravante, N.T.)

2 Relação traduz três termos em alemão: Verhältnis, Beziehung e Relation. Para não sobrecarregar o texto, indicaremos, entre colchetes, apenas as ocorrências de Beziehung e de Relation, ambas em menor número. Na ausência de indicação, relação traduz Verhältnis. (N.T.) 
está plenamente formado, são relações de poder. Sua estrutura interna de poder, designamo-la dialética [dialektisch] no sentido objetivo. A dialética [Dialektik] no sentido subjetivo - o modo de pensar dialético - possui seu objeto específico no poder do abarcar, e, de fato, não apenas na medida em que ela é [uma] lógica, mas sim como teoria da efetividade [Wirklichkeit] em geral. Pois a unidade de conceito e realidade, que é como o pensamento dialético define a efetividade, repousa ela mesma no fato de que o conceito, como afirma Hegel várias vezes, "abarca a realidade” [über die Realität übergreift].

2. Mas o pensamento dialético não seria o que é caso não refletisse limites. Em seus limites ele colide no pensamento da contradição. Contradição [que], entendida dialeticamente, indica a crise do poder. Correspondentemente, com sua resolução, anuncia-se o que está além da dialética: o mútuo reconhecimento dialógico. ${ }^{3}$

3. Nas determinações de reflexão, entre as quais a Lógica inclui [einreiht] a contradição, o poder já é manifesto: cada uma delas é "o determinado [das Bestimmte] que (...) subjugou seu passar ou infletiu sua reflexão em outro em reflexão em si" (L II 22). Uma determinação de reflexão decerto se relaciona com o poder também numa forma refletida. Segundo Hegel, oposição e contradição resultam de constelações nas quais a identidade e a diferença se dirigem uma à outra. A identidade absoluta e a diferença absoluta são porém as determinações da própria estrutura de poder, que o absoluto - que finalmente emergirá como conceito - ocupa. Se o conceito propriamente dito abarca seu outro, então ele é ele mesmo e também não é ele mesmo, simultaneamente idêntico a si e diferente de si. Uma estrutura semelhante, embora num nível mais baixo, deixa-se perceber na essência, em cuja figura [Gestalt] o conceito aqui se antecipa [auftritt]: a essência é reflexão, e a reflexão [é] um relacionar-se [Beziehen] consigo mesmo que, enquanto [um] diferenciarse de si, conserva a igualdade consigo. Que a identidade seja originariamente "o mesmo que a essência” ( $L$ II 26), esclarece plenamente o seguinte: ela também é idêntica à diferença absoluta, [à diferença] originária, e isso precisamente porque em ambas se determina o mesmo, a essência. No princípio, não se apresentam nem a identidade para si nem a não-identidade para si, mas o Absoluto como identidade da identidade e da não-identidade. A constituição assim refletida do seu poder possui em si a peculiaridade de que ela, por sua vez, reflete infinitamente: uma vez que

\footnotetext{
3 As teses hegelianas [bei Hegel] relacionadas à contradição, que "prescrevem" à cadeia de raciocínio singularmente complexa da Lógica certas estações, deixar-se-iam fundamentar suficientemente apenas a partir de uma interpretação nuançadora que siga o curso do texto do segundo capítulo da Lógica da Essência. Espero brevemente ser capaz de produzir [vorlegen] uma tal interpretação no contexto de uma exposição detalhada da teoria dialética da contradição. (Nota do autor - doravante, N.A.)
} 
não se pode pensar a identidade sem a diferença, como tampouco a diferença sem a identidade, a essência compartilha com suas determinações a unidade de identidade e diferença, que ela mesma é, e de tal maneira que as determinações de essência reproduzem, em sua relação umas com as outras, sua unidade - que cada uma já é em si.

4. No absoluto já se esconde uma primeira contradição: a contradição “em si” (L II 49). Ela é imediatamente dada com a identidade da identidade e da não-identidade. Mas o porquê de ela ser meramente "em si" e não "posta" elucida-se apenas a partir de sua relação [Bezug] com o poder. O abarcar retorna à identidade como sua determinação de reflexão fundante: para o pensamento dialético, somente $a$ identidade que abarca a diferença vale como verdadeira. A contradição nela contida subsiste apenas em si porque ela, através do poder do abarcar, subjugou o outro que se the contrapõe. No submeter do outro ela também submete a contradição. A dominação da identidade sobre a não-identidade impede a eclosão da contradição no sentido do despedaçamento interno ou da divisão do um e do mesmo em si e em seu contrário. Ela impede assim que o poder conferido ao efetivo pelo absoluto se inverta na total impotência, redundando na perda da existência. "Algo é vivo", diz Hegel, "somente enquanto contém em si a contradição, e de fato [algo] é esta força de comportar e sustentar em si a contradição. Quando todavia um existente não é capaz de abarcar (...) em sua determinação positiva simultaneamente sua determinação negativa, então ele não é a unidade viva mesma, não é fundamento, mas é levado pela contradição ao fundo" (L II 59).

5. Na sua identidade, identidade e não-identidade constituem o mesmo "todo" (L II 33), o pura e simplesmente todo, [e] como tal, o absoluto é a verdade. A identidade abarcadora, que em sua função de totalidade, provê o solo a todas as determinações de reflexão e justamente por isso é "muito mais a falta de determinação [Bestimmungslosigkeit]" (L II 23), torna-se determinada, [uma] determinação da diferença que diferencia, enquanto ela mesma se rebaixa a momento e a esse contrapõe seu outro como momento correlativo ( $L$ II 28). O poder do abarcar - esse é o domínio do todo sobre o outro, que ele contém em si como seu próprio momento.

6. Identidade e diferença são, enquanto o todo [Ganze], ambas, unidade de identidade e diferença. Esse mesmo todo, precisamente a unidade de identidade e diferença, é posto portanto em “determinidade” opositiva, ora como identidade, ora como diferença. Segundo uma mudança de perspectiva que terá de ser ratificada logo adiante, Hegel chamará uma de positivo, a outra de negativo. ${ }^{4} \mathrm{~A}$ vagueza de

4 A exposição simplificadora, que omite a entredeterminação [Zwischenbestimmung] da diversidade, 
tais determinações serve inteiramente ao seu propósito, na medida em que indica que, em virtude da igualdade de conteúdo, a determinidade bilateral implica uma infinita determinabilidade. Como figuras refletidas do ser e do nada, negativo e positivo pertencem ambos, por um lado, ao ser desmascarado como aparência e, por outro, à essência, de tal maneira que eles apontam para a relação de essência e ser, enquanto o positivo indica o ser e o negativo a essência, mas também, inversamente, aquele indicando a essência e esse o ser. Ambos são determinações do ser-aí [Dasein] tecida a partir do ser e do nada; o positivo preserva a imediatidade, e o negativo, a nadidade da aparência. No início da lógica da essência, Hegel demonstrara como as duas disposições da aparência compõem o absoluto ser em si e a absoluta negatividade da essência mesma ( $L$ II 11). Agora, como se sabe, ele opera não apenas com um conceito positivo de positivo e um negativo de negativo, mas também com um conceito negativo de positivo e um positivo de negativo. Se nos detivermos diante do significado negativo do positivo, então devemos dizer: na medida em que Hegel verte o ser em si absoluto para o conceito de positivo, ele o caracteriza por aquele trajeto em direção à essência, do qual o ser emerge como a positividade do subsistente [Bestehenden]; ao que corresponde, por outro lado, o fato de que a mais íntima essência da essência repousa em sua negatividade absoluta. Não obstante, no "falar" (L II 32) a língua 5 , na qual as determinações de reflexão, como todas as determinações do pensamento, estão "assentadas", pressuponho sempre o positivo como o um, para a ele contrapor o negativo como o outro. Porém, quando não é indiferente o que ponho como o um e o que ponho como o outro, pois o positivo é o “em si mesmo positivo" e o negativo, o “em si mesmo negativo"( L II 45), ao fim e ao cabo cruza meu caminho o pura e simplesmente um, que, por não passar no outro como o algo [passa], pode ser e permanecer o que é, pois é também o que não é: precisamente o outro, ao passo que esse, o negativo, revela-se como o outro enquanto tal, o qual sequer é o que é; pelo contrário, somente na relação [Beziehung] com o um como seu outro possui ele seu ser. 0 poder do abarcar é posto ali, portanto, enquanto poder, como o poder do absoluto, e aqui, pelo contrário, como impotência, como o ser precário do finito, que, segundo a conclusão do capítulo da contradição, é na verdade o "não-ser".

7. Chega-se assim à crise do poder, logo que um e outro, apesar de serem um, cindem-se em duas totalidades. Visto que o poder é poder da razão, sua crise só pode ter sido causada por seu adversário: o entendimento. Certo, a lógica da essência contém "as categorias da metafísica e da ciência em geral”; mas as contém

consequentemente também deve se abster de [mostrar] que - e de que modo - a unidade de identidade e diferença se desenvolveu para uma tal [unidade advinda de] igualdade e desigualdade. (N.A.)

5 Ou seja, no uso corrente da língua. (N.T.) 
“como resultados do entendimento reflexivo" (Encyclopädie § 114). A aqui referida confusão da verdade com uma aparência que, em comparação com o início da lógica da essência, tornou-se potencializada e [ganhou um caráter] pejorativo, resulta do fato de que o entendimento, enquanto uma faculdade singular, é ao mesmo tempo um órgão da razão. Enquanto entendimento, ele separa identidade e diferença, ou seja, unilateralmente dissolve a unidade que determina a relação delas em prol da diferença; noutras palavras: ele hipostasia a identidade como positivo que subsiste autonomamente e, igualmente, a diferença como negativo sendo para si. Todavia, conquanto não apenas "assuma" os lados distinguidos dessa maneira abstrata "como autônomos", mas, conduzido pela razão, "ponha também sua relatividade” (ibidem), a unidade permanece-lhe obscura. Tal unidade, revela-a o progresso racional no desenvolvimento dos conceitos de entendimento, quando põe a descoberto a identidade da identidade e da não-identidade, que se escondia nas determinações de reflexão, mas fora ocultada pelo entendimento - e através dessa explicação chega, via superação [aufhebt], a uma determinação mais alta.

8. Da cisão - típica do entendimento [verstandesmaessig] - do mesmo todo em duas totalidades se origina a contradição específica da oposição. Ela consiste em que "os lados que se tornaram autônomos" ( $L$ II 42) tanto se contêm quanto se excluem mutuamente. Eles contêm um ao outro como momentos e excluem-se como totalidades. Se cada um deve ser o todo, então eles devem conter o seu respectivo outro como momento; mas, se cada um é de fato o todo, então simultaneamente exclui o outro, a saber, o outro como todo, que ele mesmo é. A reciprocidade da implicação dos momentos requer obrigatoriamente a igualmente recíproca exclusão das totalidades, que somente em virtude dessa implicação são o que são. Logo, através da sua divisão, surge do poder do abarcar uma luta pelo poder: a contradição na figura antagonista do conflito. Se nos fosse permitido formular, com Habermas, a lógica da contradição como lógica das reivindicações de reconhecimento [Geltungsansprüchen], a contradição específica da oposição se reduziria a que a reivindicação de um dos lados de ser o todo provoca a objeção do outro, o qual exige o mesmo todo para si. Como tal disputa, a "contraposição" se apresenta não apenas sob o ponto de vista do conter, mas também sob o do excluir. Se o conter é um submeter, o excluir é um negar: na medida em que o um exclui o outro, ele o define como "não-ser". 0 conceito do não-ser, que, de início, apenas tornara o outro cognoscível como aquilo que o um não é, ou seja, indicara o não-ser-o-um do outro, devém agora sinônimo de um não-ser que se compreende como inexistência - que, como não-ser do outro, também é, em função da reciprocidade do processo de negação, não-ser do um: “o seu outro, que cada [um] contém, é então também o não-ser daquele no qual [0 outro] deve ser contido apenas como momento" (L II 42). Embora o um, para que ele 
mesmo possa ser, pressuponha o ser do outro, isso significa seu próprio não-ser, já que ele ao mesmo tempo só é sob a condição do não-ser de seu outro.

9. A contradição da oposição, por um lado, não é mais meramente contradição em si, mas precisamente sua negação. A contradição em si se nega - ou seja, esvai-se enquanto contradição - quando se duplica, na medida em que o poder d[aquil]o que abarca se defronta com o poder contrário, exercido por aquilo que é abarcado, que, por seu turno, também abarca [aquilo que o abarca]. Por outro lado, a contradição reinante na oposição ainda não está propriamente posta enquanto tal. 0 conceito hegeliano da contradição posta se orienta pelo principium contradictionis aristotélico. Segundo sua concepção, uma contradição só pode valer enquanto posta, a rigor, quando a ela o mesmo efetivamente se aplica e também não se aplica - e, na verdade, não apenas simultaneamente, mas também na mesma "consideração". A demanda por negatividade, emitida no princípio [Satz] da exclusão da contradição [do reino do conhecimento] como algo que não pode ser satisfeito, é de fato satisfeita pela contradição da oposição - apesar de toda a discussão sobre a interpretação kantianisante de Hegel do "não A" em "Não-A". O fato de que o um contém o outro e no entanto o exclui pode ser expresso negativamente: ambos se contêm e, ao mesmo tempo, não se contêm. Mas, na medida em que o excluir, como foi dito, se relaciona [bezieht] ao outro como o todo, e o conter, pelo contrário, se relaciona ao outro como momento, o um e o outro do um e [o outro] do outro não devem ser mencionados no mesmo sentido [Hinsicht].

10. A [contradição] da oposição se move entre a contradição que existe meramente em si e a[quela que foi] posta, como uma contradição já em si posta. A diferença na unidade, apreendida nos moldes do entendimento, consiste, quando perscrutada pela razão, em que cada lado - quando, ao contrário, é efetivamente um com o outro -, nada contém além do outro, [e portanto,] segundo o seu conteúdo integral, é equivalente ao outro. A contradição devém posta através da reflexão, que descobre que o conter é mais do que implicação, a saber, equalização total. Pois nesse ponto o um contém o outro no mesmo sentido em que também o exclui: como o todo. Com a totalização do conter, todavia, o excluir ganha um novo aspecto. Se o um não contém senão o outro, então ele põe o outro ao se pôr, do que decorre que [ao se pôr,] ele exclui a si mesmo. Com a passagem da oposição contraditória à contradição enquanto tal, a exclusão recíproca se evidencia como auto-exclusão. Eo ipso o contradizer-se, que era o contradizer mútuo dos lados contrapostos, torna-se igualmente um contradizer a si mesmo de cada lado para si. Uma autocontradição é uma contradição posta no exato sentido indicado por seu nome: o que contradiz a si mesmo é o pôr-se que se faz pôr do outro. 
11. A crise chega assim ao apogeu. Com a totalização do conter, o poder abarcador originário sucumbe a si mesmo; e, com a reflexão do excluir, tanto o um quanto o outro voltam-se, em sua pulsão de negação, contra si mesmos. "Eles se dirigem ao fundo [zugrund]" (L II 51); ou seja: na medida em que destroem um ao outro, destroemse a si mesmos. Pertence à radicalidade da crise que, tão logo se estabelece, tal constelação arrasta os lados participantes com o automatismo de uma fatalidade. O fato de que o um, ao pôr-se, põe o outro: "o traduzir-se de si em seu contrário", enquanto "infatigável desaparecer dos contrapostos em si mesmos” (ibidem) é, nesta infatigabilidade, também o infinito, "eterno" retorno do mesmo. A inversão [Umschlag] do pôr-se em posição do seu oposto acontece tanto para o um quanto para o outro; ambos se descobrem como seu contrário sem nada terem feito para isso.

12. Por conseguinte, a contradição só se pode resolver caso o um se ponha em liberdade como o outro. Para isso, porém, ele precisa se libertar da estrutura que conjurou o estado de crise [Krisenzustand]. Se o pôr-se não deve novamente se inverter em posição do outro, então o pôr-se como o outro não pode de modo algum significar que o um, enquanto o todo, ponha o outro como seu próprio momento. Pelo contrário: o pôr agora requerido deve precisamente negar o pôr do momento através do todo. 0 um põe-se como o outro, que ele pusera como seu momento, quando ele o retira a partir de si. Ao dispensar o outro de seu ser-posto como momento, liberta-se ele próprio da relação de dominação que impusera ao momento a junção a ele como todo. Na medida, porém, em que ele consegue sua própria liberdade, ele também garante ao outro seu próprio ser-para-si: seu domínio sobre o outro, [outrora] deslumbrado pela aparência [Schein], [agora] cede lugar ao reconhecimento de sua verdadeira autonomia, uma autonomia que, embora exclusivamente impossível [ausschließlichausgeschlossen], ${ }^{6}$ não se lhe defronta - ao um - como estranha; pois [agora] ele põese a si mesmo como o outro ou no outro.

\footnotetext{
6 Optou-se por uma tradução literal do jogo de palavras empregado por Theunissen nessa passagem. A tradução literal, parece-nos, exprime de maneira adequada o pensamento aqui elaborado, qual seja, o de que a verdadeira autonomia só se pode sustentar pela autonomia do outro. Noutras palavras, uma autonomia que se queira exclusiva é necessariamente ilusória: a autonomia que busca se sustentar pela supressão da autonomia do outro é mera aparência (N.T.).
} 
1. Segundo os Grundrissen der Kritik der politischen Ökonomie (GR), para que se possa compreender o capital "em sua determinidade formal [Formbestimmtheit] específica", deve-se apreendê-lo como uma relação de produção "refletida em si". 0 capital deve ser tomado como a "relação de capital" cujos membros - ele próprio e o trabalho assalariado -, do mesmo modo que as determinações de reflexão, "relacionamse [beziehn] um com o outro e diferenciam-se um do outro" (GR 216/17). Mas a forma específica do capital é, em essência, historicamente determinada. De acordo com a tese de Marx, a lógica das determinações de reflexão - que, aparentemente, não é de modo algum aplicável à história factual - abre precisamente o acesso a uma compreensão [Verständnis] concreta e histórica do capital. Ora, relações de produção são sempre relações de dominação [Herrschaftverhältnisse]. Porém, o capital se diferencia das "relações imediatas de dominação e servidão" de formações sociais anteriores pela mediatidade de sua dominação. Porque sua dominação é mediada - e de fato, mediada precisamente no sentido das relações refletidas em si -, o reconhecimento de sua singularidade histórica depende da aplicação das determinações de reflexão.

2. Somente no trajeto dos Manuscritos Parisienses (1944) para os Grundrisse (1857/58) Marx obteve uma consciência suficientemente clara das dificuldades de sua tentativa de adaptar a lógica das determinações de reflexão à relação historicamente dada de capital e trabalho. Sua ingenuidade inicial repousa na crença de que o desenvolvimento lógico das determinações de reflexão se deixaria projetar sem mais na história factual, ou seja, deixar-se-ia transportar [uebertragen] num movimento em que tanto ele mesmo quanto sua contrapartida real poderiam se integrar inalterados e não reduzidos. De acordo com a conclusão do segundo manuscrito de 1844, capital e trabalho têm que percorrer um trajeto que se inicia com uma "unidade" - de início imediata, e então mediada - e que, através da a "oposição de ambos", a qual se aprofunda numa “oposição de cada um contra si mesmo", conduz a uma "colisão dos reciprocamente opostos" 7 . Marx apreende a unidade como unidade da identidade e da diferença; a imediata - evidentemente nos moldes da lógica do ser - como unidade ainda não desfeita, e a mediada - nos moldes da lógica da essência - como uma unidade dentro de si diferenciada. Seu conceito de oposição chama de luta pelo poder da exclusão recíproca, a qual também define a oposição contraditória de Hegel, pelo nome: capitalista e trabalhador excluem-se "mutuamente", no sentido de que cada um sabe o outro como seu próprio "não ser-aí [Nichtdasein]", e por isso

7 Sigo aqui a interpretação de H.-J. Lieber e P. Furth (Karl Marx, Frühe Schriften I, Darmstadt 1971, S. 584). (N.A.) 
procura "arrancar do outro o seu ser-aí". Analogamente, Marx descreve a "oposição de cada um contra si mesmo" de acordo com o modelo hegeliano da contradição pura e simples [schlechthin], na qual os membros da relação [Beziehungsglieder] invertem-se um no outro e portanto excluem a si mesmos. 0 movimento lógico deve portanto ser igualmente um movimento histórico. Marx não apenas espera uma "resolução" da contradição unicamente por uma “colisão", à qual se deve chegar através da tarefa histórica da revolução proletária; mas também pensa o início do movimento historicamente: a unidade imediata aponta evidentemente para a época pré-capitalista, na qual ainda não havia qualquer separação entre os proprietários privados dos meios de produção e os despossuídos vendedores de sua força de trabalho, enquanto a unidade mediada alude à harmonia do capitalismo inicial que, segundo Adam Smith, conservava-se na própria separação: capital e trabalho [estão] "de fato separados e estranhados [entfremdet], mas se elevam e promovem reciprocamente enquanto condições positivas".

3. Os Grundrisse e o Capital distinguem-se dos Manuscritos Parisienses primeiramente de maneira negativa, através de uma renúncia do paralelo entre o longo trajeto da lógica da identidade à contradição e o correspondentemente extenso curso do feudalismo até a autossuperação [Selbstaufhebung] do capitalismo; em ambas as obras, Marx se contenta com uma verificação [Nachweis] da contraditoriedade do capital plenamente desenvolvido. Tal aplicação restrita das determinações de reflexão decorre de uma redução da perspectiva histórico-teórica. A crítica qualificada da Economia Política não pretende expor o fenômeno histórico do capitalismo, mas sim, antes de tudo [zunaechst einmal], o conceito geral do capital. Assim, a história, na medida em que serve para mais do que a mera documentação das lutas sociais, só pode ser tematizada sob pontos de vista que repousam nesse conceito. Sob o foco da teoria, ela se apresenta exclusivamente como o terreno no qual o conceito geral de capital se realiza [sich realisiert]. Todavia, ela é a realização do conceito de capital em uma pluralidade de sentidos: 1. como surgimento das únicas condições históricas reais sob as quais o capital pode vir ao mundo de acordo com seu conceito; 2 . como o movimento que se estende da circulação sobre a produção até a reprodução, no qual, antes de tudo, desdobra-se [entfaltet] a estrutura conceitual completa do capital; 3. como o desenvolvimento histórico ulterior - entendido de maneira restrita - do capital plenamente desdobrado, na medida em que tal desenvolvimento é regido por leis tendenciais de desenvolvimento que podem ser derivadas de seu conceito. Sua gênese histórica real certamente não pode ser derivada de seu próprio conceito. O "processo de separação do trabalhador de suas condições de trabalho", como "processo que cria a relação de capital" (MEW 23, 742), é também o local de nascimento das classes, em que os próprios "capital" e "trabalho" se separam. 
Esclarece-se assim como Marx insere o caráter classista da sociedade burguesa em sua teoria hegelianizadora das relações de produção refletidas em si: por um lado, ele lhe atribuirá um lugar central na lógica das determinações de reflexão; por outro, ele se abstém de qualquer tentativa de derivar tais relações da referida teoria. Essa aparente falta, acompanhada de uma indeterminidade dos conceitos "capital" e "trabalho" determinável apenas lógico-estruturalmente, deve-se efetivamente à consciência apropriada dos limites de toda remissão [Rueckfuehrbarkeit] da história factual à estrutura lógica.

4. Já de início chama a atenção o fato de que a crítica da economia, na sua aplicação da lógica das determinações reflexivas, não apenas a restringe, mas também a expande - ainda que num outro sentido [Hinsicht] -, através do uso de categorias "tardias" como "fundamento" e "forma", "substância" e "conteúdo". De fato, com o avanço da lógica da essência, toda a lógica do conceito já se faz presente na análise da contraditoriedade da relação de capital. Evidencia-se assim manifestamente que Marx presume [encontrar] a dialética reflexiva dessa relação no material de uma história que, enquanto realização do conceito de capital, imita o abarcar [Übergreifen] do conceito puro e simples [schlechthin] sobre "seu outro". Consequentemente, a relação capital-trabalho tem também em si mesma a estrutura da relação [Beziehung] do conceito com sua realidade, de modo que a relação [Beziehung] entre conceito e realidade materialisticamente se inverte, e a realidade revela [enthuellt] a verdade sobre o conceito. A verdade sobre o capital, que progressivamente se reconstrói, manifesta-se apenas com sua reprodução; pois, como já foi dito, somente aqui é concluída a constituição de seu conceito. Por causa de sua afinidade com o conceito, a reprodução do capital está ligada à produção e à circulação de mercadorias (no sentido determinado do "intercâmbio de capital e trabalho") do mesmo modo como, em Hegel, o conceito que é aí para si [está ligado] à essência e ao ser. Hegel observa oportunamente ( $L$ I 44) que a essência ainda se relaciona com [Relation zum] o ser "como o que lhe é também exterior", enquanto o conceito, em sua autorreferência, revoga tal relação [Relation]. De modo análogo, segundo Marx, somente a reprodução dissipa a aparência de que a produção, vista isoladamente, ainda está acometida: a de que a circulação the seria exterior, uma esfera pré-existente [vorgegebene]; apenas como reprodução a produção se torna aquilo que ela já é em si: “o que abarca [das Uebergreifende]”(GR 20). Na medida em que a produção é o que abarca, a contradição com a qual a verdade sobre o capital vem à luz deve com efeito corresponder rigorosamente à da lógica da essência: se Hegel atribui a contradição que é meramente em si à esfera do ser e estende a [contradição] posta por toda a esfera da essência (Enc. § 114), Marx considera a unidade imediata de valor de troca e valor de uso na mercadoria circulante como a 
contradição "embrulhada" [eingehuellte] que se manifesta apenas quando valor de troca e valor de uso, como capital e trabalho, defrontam-se um com o outro numa relação mediada, refletida (GR 117 ff.). Porém, o poder do abarcar, evocado pela contradição, leva Marx inevitavelmente ao conceito do conceito: a "subordinação do trabalho pelo capital”, ele a pensa nos termos da lógica do conceito, i.e., como “subsunção”.

5. Na diferença e identidade entre subsunção "formal" e "real", Marx mostra como o domínio do capital, que ele já exerce enquanto conceito abarcante, ao mesmo tempo é e vem a ser realidade histórica. A subsunção formal - que já ocorre na compra e venda da mercadoria força de trabalho - aparece, enquanto condição de possibilidade da produção de mais-valor em geral, com o conceito do capital; realmente [reell], porém, o capital pôde subordinar o trabalho apenas quando conseguiu penetrar o próprio modo de produção, ou seja, através da transformação dos instrumentos de trabalho em maquinaria; portanto, em última instância, através da aplicação da ciência ao processo de produção, com o intuito de encontrar os meios adequados à produção do mais-valor relativo (MEW 23, 532/33). Ao superar [aufheben] a diferença na unidade da subsunção, Marx ao mesmo tempo medeia conceito e história. Por um lado, a história meramente executa o veredito que o conceito geral do capital já no princípio enunciara; a subsunção real é "real" em relação [in bezug] ao terceiro [termo do silogismo]: trata-se da verdadeira realização histórica do conceito. Por outro lado, a subsunção formal é também, enquanto tal, um acontecimento. Trata-se, com efeito, de um acontecimento que oferece uma dupla perspectiva. A constituição, para si formal ou ideal, através da qual o capital põe o trabalho na determinidade formal do trabalho assalariado, acontece de fato na realidade histórica, como sujeição real. Considerado sob o aspecto formal, o trabalho, enquanto trabalho assalariado posto pelo capital, deve ser essencialmente pressuposto como trabalho; sob o aspecto real, ele aparece como historicamente dado. 0 "processo dialético de gênese", no qual Marx resolve [auflöst] a constituição do conceito de capital, é portanto "apenas a expressão ideal do movimento efetivo no qual o capital devém” (GR 217).

6. A distinção entre as subsunções formal e real obriga Marx a uma alteração essencial da estrutura subjacente às determinações de reflexão. Ele adota a estrutura hegeliana, uma vez que concebe a dominação do capital sobre o trabalho como a de um todo que opõe ao momento a que ele mesmo se reduz [herabsetzt] "seu outro", enquanto seu próprio momento. Mas primeiro ele completa a estrutura de poder que repousa no modelo da totalidade; e então assume que ela evoluiria historicamente, com o progressivo desenvolvimento do capital, até sua completude. Como momento 
do capital, o trabalho assume a forma do "capital variável"; com ele se defronta o "constante" (cf. MEW 23, 224), momento ao qual o próprio capital se reduz. A conexão dos dois momentos, contudo, é condicionada pelo funcionamento do capital enquanto todo abarcador. Enquanto o capital, representado no processo de produção pelo [seu] momento constante, é determinado de maneira puramente objetiva (enquanto suprimento de meios de produção e matérias-primas), à sua função de totalidade corresponde, além de seu significado superficial [vordergruendig], objetivo, também um recôndito [hintergruendig], subjetivo: o todo se põe não apenas como soma dos valores, mas é também pressuposto, do modo descrito, como a classe dos capitalistas. Sua dominação é exercida factualmente [faktisch] por aqueles que, enquanto proprietários privados dos meios de produção, detêm o poder de controle sobre o processo de produção como um todo [gesamten Produktionsprozess]. Tal dominação já fora instituída pelo ato da subsunção formal, que coincide com a constituição originária [Urkonstitution] do capital. Porém, por meio das "transformações [Veraenderungen] (...) sofridas pela relação entre capitalista e trabalhador assalariado no transcurso do processo de produção", o trabalho degradado a momento do capital cai além disso mais e mais sob o domínio daquele momento em que o capital mesmo se constitui [sich selbst macht]: "Não é mais o trabalhador quem emprega os meios de produção, mas os meios de produção que empregam o trabalhador" (MEW 23, 328/29; C, I, 244). Mas eles são tais "meios de exploração e dominação" (MEW 23, 794) nas mãos do capitalista, que por sua vez os emprega. Como dominação de um mero momento, a [dominação] da maquinaria baseia-se na total e originária "dominação do capitalista sobre o trabalhador" (MEW 23, 765); pois a maquinaria possui uma qualidade especificamente capitalista somente na medida em que nela se materializa a pressão que sobre ela exerce a propriedade privada.

7. Em Hegel, chega-se à crise do poder porque o mesmo todo se cinde em duas totalidades. Para Marx, é impossível fundamentar a contradição dessa maneira; pois, em seu modelo, somente o capital é posto como totalidade. Segundo sua formulação, tal alteração corresponde também à história factual: o capital já se pôs como totalidade; o trabalho, ainda não, pois ainda não se constitui como sujeito de classe [Klassensubjekt]. Com isso, também a contradição ainda não está posta (no sentido forte de Hegel); ela somente é posta de fato através da "colisão" que a resolve [aufloest], ou melhor, que resolve a constelação que a causa - noutras palavras: pela tomada do poder pela classe trabalhadora. Todavia, é "necessário" que ela seja posta, na medida em que - e apenas na medida em que -, embora não seja uma consequência inevitável, a autoposição do trabalho como totalidade seja sim uma consequência lógica da contradição que domina [durchherrscht] a relação 
de capital.

8. Marx se dirige à contradição na estrutura da relação de capital quando atribui a oposição do capital contra o trabalho à do trabalho capitalizado contra si mesmo. Seu ponto de partida velado [verborgenen] é constituído pelo reconhecimento de que a coincidência que subsiste para o capital entre seu conceito e sua realidade não é, na realidade mesma ou em si, coincidência alguma. Assim, Marx identifica o capital como o verdadeiro suporte daquela contradição que Hegel imputa ao finito enquanto tal: o fato de que a correspondência do conceito e da realidade é, simultaneamente, uma não-correspondência. ${ }^{8}$ Apenas aparentemente é que o capital posto em sua totalidade é a substância consumada como sujeito, e apenas aparentemente seu conteúdo encontrou a forma a ele adequada. A "substância do capital" subsiste na riqueza infinita do mundo das mercadorias. A "substância comum de todas as mercadorias" é o trabalho objetivado - o qual, por seu turno, brota do trabalho vivo. Assim, conforme toda a sua substância, o capital não é ele mesmo, mas sim trabalho9. A oposição entre trabalho objetivado (morto) e trabalho fluido (vivo) revela-se como a realidade dos momentos em que, de acordo com sua determinidade formal específica, o capital se decompõe, i.e., do capital constante e do capital variável. Assim composto, o capital total [Gesamtkapital] possui seu fundamento em seu contrário.

9. Assim, a constituição formal recíproca dos membros da relação de capital é subvertida por uma constituição material unilateral do capital pelo trabalho. A subsunção formal através da qual o capital imprime no trabalho a forma do trabalho assalariado passa a existir através da - em si dialética - "produção do trabalho assalariado como seu fundamento criador comum" (GR 189). A dominação do capital sobre o trabalho inverte-se simultaneamente em sua autodominação. Quando “o capital aparece como produto do trabalho", o "trabalho objetivado" revela-se na tirania dos meios de produção antes de tudo "como dominação, comando sobre o trabalho vivo"; evidencia-se que o trabalho vivo criou a partir de si mesmo o "poder estranho [fremde]" do trabalho morto, que se lhe contrapõe autonomamente. Mas como, junto com o momento da relação de capital que lhe é contraposto, o trabalho vivo produz igualmente a "relação" como um todo, ele consequentemente insere a própria totalidade que o abarca no poder do abarcar. Em ambas as direções, a força

8 Veja-se Theunissen, M. (1975). „Begriff und Realität. Hegels Aufhebung des metaphysischen Wahrheitsbegriffs" [Conceito e Realidade. A superação hegeliana do conceito metafísico de verdade]. In: Denken im Schatten des Nihilismus. Festschrift für Wilhelm Weideschedel. Ed. A. Schwan. Darmstadt. (N.A.)

9 Veja-se MEW 23, 247 (C, I 1, 189): "O capital é trabalho morto que só se vivifica vampirescamente, sugando trabalho vivo, e vive tanto mais quanto mais deste sugar". (N.A.) 
de trabalho vivo paradoxalmente obedece a um "poder que a domina através de sua própria atividade ${ }^{10 "}$ (GR 357).

10. Aautocontraditoriedade do capital é definida pelo fato de que esse é, na profundeza de sua substância, o contrário daquilo como ele se apresenta segundo sua forma. Ela encontra sua expressão especular na autocontraditoriedade do trabalho capitalizado: substancialmente, ele é tudo; formalmente, pelo contrário, nada. Porque o trabalho na forma do trabalho assalariado se põe de fato como o todo, mas o todo é o "seu próprio não-ser”, seu “processo de efetivação [Verwirklichungprozess]” resulta [hinausläuft] num "processo de anulação [Entwirklichung]" (GR 358). Entretanto, precisamente na autocontraditoriedade do trabalho capitalizado repousa o ímpeto [Antrieb] de se libertar, ou seja, de pôr também aquilo que ele já é em si. Marx assinala o "ponto de viragem" - modo como Hegel designa o "superar da contradição” (L II 496/97) quando fixa [festmacht] no próprio trabalho vivo a oposição do trabalho contra si, que ele encontrara na relação entre trabalho vivo e trabalho objetivado. 0 capital ocupa o lugar do positivo (no sentido daquilo que subsiste) e o trabalho, como "nãocapital", o do negativo. Caso porém o não-capital seja "posto como tal", noutras palavras, caso ele seja posto em sua negatividade - o que, concretamente, significa que o trabalho realizaria a anulação [Entwirklichung] de sua atividade -, então emergirá no negativo a positividade, a qual, segundo a lógica das determinações de reflexão, consiste em que o negativo de fato "baseia-se positivamente em si mesmo" (L II 44). O trabalho não objetivado é, "apreendido negativamente", a completa ausência do objetivo; mas, "apreendido positivamente", ele é a "negatividade referida [beziehend] a si mesma" (que é o modo como Hegel concebe o sujeito), a "própria existência subjetiva do trabalho" (GR 203). A fonte da qual flui a substância do capital não apenas já comporta em si o todo que deve ser posto através da sua autolibertação; a ela já pertence em si a subjetividade, enquanto a que deve pôr o todo [als die das Ganze zu setzen ist]. Contudo, o capital admite a subjetividade de seu outro meramente como determinação do negativo e, portanto, apenas como reprimida [unterdrueckte]. O movimento revolucionário não extrai sua força de um resíduo porventura poupado pela subsunção, mas sim do sofrimento provocado por um aparelho de dominação que o sujeito real só poderá libertar através de sua não conformação [Verweigerung].

Recebido em: 07.02.2019

Aceito em: 12.04.2019

10 Ou seja, através da atividade do próprio trabalho vivo (N.T.) 